\title{
Research on Tourism Development Strategy under the Strategic Pillar
}

\author{
Industry \\ Dongyan Ma ${ }^{1, a}$ Chao Zhang ${ }^{2, b}$ Jiange Xue ${ }^{1, a}$ \\ ${ }^{1}$ Pan Zhihua College, Sichuan, China, 617000 \\ ${ }^{2}$ Public management College of Sichuan University, Sichuan, China 610044

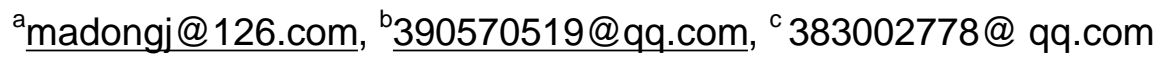

\begin{abstract}
Keywords: Tourism; Strategic Pillar Industry; Development Strategy
Abstract: Building tourism industry into a strategic pillar industry is the inevitable choice that the Chinese government follows the market rule of the tourism industry development, facing the new situation, new feature and new requirements in the new period. With strategic position jumping of tourism industry in our country, it will really enter the new development stage of Capital and industrial convergence drive. Therefore, in order to solve the new situation and the new problem of facing, we must strengthen the overall planning with a new perspective and ideas.
\end{abstract}

\section{Introduction}

According to the world tourism organization prediction, China will become the world's largest inbound tourism receiving country and the world's fourth largest outbound tourists` source country by 2020 . In order to adapt to the future trend of the tourism development, give full play to the unique tourism resources advantage, promote the rapid and sound development of Chinese tourism industry, the State Council has issued opinions about accelerate the development of tourism which is an important strategic measures in the new period that has been putting forward to at the height of the implementation of scientific development outlook. Tourism is defined into a national strategic pillar industry. This is unprecedented positioning for tourism industry, is for the first time since the founding of the People's Republic of China and is the new era of the landmark, which will provide the unprecedented historical opportunity and policy environment for the development of tourism in China.

\section{The understanding and recognizing of strategic pillar industries}

The strategic pillar industry is the dominant industry in the country`s industry group. At the same time, it has important strategic significance and support for a country's economic and social development. Strategic pillar industries contain two levels namely strategic industries and pillar industries. The so-called strategic industry is defined as the survival and fain developing industry about a country or region. It has the possibility of the leading industry and pillar industry. The industry belongs to national strategic industry related to national fundamental competitiveness, national security, the realization of state strategic target and affecting national political status. Pillar industry refers to have the important strategic position in national economy, the industrial scale occupies larger share in the national economy and plays a role of supporting industries or industrial clusters. Often by leading industry (the small, limited impact on regional economic growth, but represents the direction of the industrial progress, development potential, promising industry) 
development, achieving a large-scale (dominant industry) becomes the pillar industry in the future. Strategic pillar industry is to point to the origin industry whose development speed is fast and potential is large, having the function of guiding and promoting the economy as a whole in the national economy. Tourism as a strategic pillar industry of national economy is not only the important measures of sustaining economic growth vexpanding domestic demand adjusting structure but also a long-term strategy of keeping economy stable and continuous development in China.

\section{There are existing problems that tourism will be built strategic pillar industry in China.}

\section{Tourism volatility caused by the vulnerability of tourism}

The vulnerability of tourism refers to that tourism is more sensitive to external interventions and changes, it is vulnerable to the interference of various uncertainty factors and external environment changes of force such as the war, terrorism, political unrest, economic or financial turmoil , natural disasters and so on. This will cause significant fluctuations in tourism supply and demand and make originally stable and balanced tourism market chaos. The reason of the tourism industry of vulnerability is: all kinds of unexpected events with great unpredictability and tourism industries highly dependent and comprehensive. Too much external factors will lead to that tourism is extremely easy to have the chain reactions and make the tourism industry become the most sensitive part of a society. In this case, tourism industry is relatively passive, lack of the ability to guide the market consumption and the vulnerability of tourism further show. Volatility caused by the vulnerability of the tourism industry has become no controversial fact. This point has the most outstanding performance in the entry and exit tourism market of various countries in the world. Tourism volatility due to the vulnerability of tourism brings various negative effects on national economy and social structure. It also brings negative influence on other industries so that various social issues are highlighted.

\section{There is still a certain gap and distance from the strategic pillar industry}

In general, the strategic pillar industry has the key indicators, that is to say that it has the big industry scale, accounting for more than $5 \%$ of the gross domestic product (GDP) and it plays a key role in regional economic growth. Besides it can induce the rise of new industries, having a wide impact on the development of the economic structure of the region and other industries, having a strong comprehensive and the development potential is tremendous. Meanwhile it has the advantages of correlation degree high, great industrial contribution rate, more employment opportunity, better comprehensive benefits. But because at present Tiao-Kuai segmentation tourism management in our country, conflicting policies from different departments; tourism enterprises small, scattered and weak; social capital into the tourist market difficulty, there are many restrictions on direct investment and indirect financing problems; the tourism market is not prosperous and tourism supply is far less than the travel demand, which has seriously hindered the sustained and coordinated development for China tourism industry, making our country tourism overall benefit not high.

\section{Some other problems are urgently solved in tourism market}

First of all, Per capita consumption level is low in domestic tourism market. Although compared with the inbound and the outbound tourism markets, the cardinal number of domestic tourism income and the people number of tourism is larger, per capita consumption is still in low consumption and low level. At the same time, the absence of farmers tourism demand. The explosive growth of the rural tourism market remains to be over time. Secondly, there generally 
exists small、 scattered、 weak and poor situation in the tourism production enterprise in our country. The lack of leading enterprises and no large tourism group brand result in the poor competition ability of the tourism industry. Again, the development of tourism products is still at the primary stage. Tourism projects to meet the diverse needs of modern tourism with the cultural added have not been fully cultivated. Finally, the poor quality of tourism service, defective tourism laws and regulations, the inadequate tourism supervision and implementation market, which lead to the problems that scenic spots and travel agencies collect fees in disorder, tour guides use guide for kickbacks, repeated violations and the order of the tourism market is in chaos. These factors significantly inhibit the development of tourism industry in china.

\section{The construction measures of building the strategic pillar industry}

In order to make Chinese tourism become bigger and stronger, further improving the ability to resist the risk and the world competitiveness of China's tourism industry, we must carry out the tourism industry's overall development、coordinated development、safe development 、 harmonious development and sustainable development. Realizing the goal of building tourism into the strategic pillar industry of national economy simultaneously needs more policies.

\section{Establishing tourism crisis management mode}

First, we should study and explore the successful experience and the various methods of disposing tourism crisis management events in other countries and regions of the world, promoting the tourism industry to generate in the elasticity of dealing with crisis and strong force to overcome political and economic unrest or natural disaster. Secondly, improve the tourism crisis policy and fund from the central to the local, improving the crisis management system from the organization and mechanism. Finally, the tourism enterprises should strengthen image planning of tourism destination during the crisis and increase the risk management efforts after the crisis so that promoting tourism industry's rapid recovery after the crisis. Through the construction of tourism crisis management mode in line with China's national conditions, to reduce the vulnerability of tourism industry, weaken the great disturbance and risk of the tourism crisis, which has become a major problem of the construction of tourism strategic pillar industry.

\section{Cultivate internationally competitive large-scale travel enterprise groups}

At present, the main bottleneck of building tourism into the strategic pillar is short of large-scale tourism enterprise groups with brand influence, great management advantages and strong market shares. So we must speed up the construction and cultivate a group of large tour groups with international competition ability. This needs in accordance with the basic rules of tourism market, actively trying various means and methods, exploring the new way to develop the main body of tourism industry. First, restructuring and optimizing the industrial structure and the industrial organization of bound tourism development, to accelerate the transformation from scale quantity to quality of the national tourism. Secondly, to further expand the industry integration, through scale expansion, obtaining the biggest market shares, creating a new space of tourism group development. Finally, make the tourism group form a rational layout of geographical network space, strengthen the industrial integration of tourism elements and regional integration efforts and construct large tourism pattern.

\section{Raise the informatization construction level of tourism industry}

The application of e-commerce can make the tourists consult or query of transportation, accommodation, tourist attractions, tourism products ,travel agencies, tourist routes and other relevant aspects of the real-time dynamic information through the computer reservation system (CRS), 3G technology, the internet or internal website and realize online e-commerce system 
functions such as the online communication、online consultation、online booking , online payment complaint handling to let the tourism price information transparency, payment facilitation, helping to improve the efficiency of tourism trade and customer satisfaction. Meanwhile, using the 3s (GPS, GIS, RS) and RFID technology (Radio Frequency Identification technology) and environmental testing protection management information technology, according to the space is relatively static and dynamic of time as well as the principle of the same space with different time distribution of stream of people, they can dispatch and shunt navigation for tourists and scenic spot relative equilibrium distribution.

\section{Intensify potency dimension of the government guiding the tourism development}

Build tourism strategic pillar industry status, especially to strengthen the government's comprehensive coordination of tourism, macro guidance and market regulation. First, increase government financial input to the tourism. It should give policy support for the key projects of the society, as well as provide motivation and policy guarantee to the growth of the new economic growth point of tourism and the promotion of the position of the industry from the following respects such as the industrial policy, finance, credit and money. Second, increase the strength of investment in science and technology. Third, the government should create favorable policy environment for fair competition and innovation. The government is supposed to construct a reliable financing channel and use the fund of market collection to promote the market development of tourism industry. At the same time, according to the requirement of scientific development, government departments are expected to establish scientific tourism development planning, effectively prevent blind construction behaviors that is repeated and low level in the tourism development, short-term behavior that quickly get rich, excessively dig vandalism, so as to guarantee the healthy and orderly development of tourism industry.

\section{Conclusions}

To build tourism into a strategic pillar industry is the choice of history and realistic choice. Therefore we should adhere to the principles of scientific development and spanning development, make the tourism become a new growth point of promoting the economic development and constantly create a new situation of the development of the tourism industry to make new contributions.

\section{References}

[1] Dian Ting, Wang Lihua : submitted to Journal of China Soft Science (2010)

[2]. Gao Liang: submitted to Journal of Open review (2010)

[3] Li Wei: submitted to Journal of Business Economic Review (2013)

[4] Su Dongshui: Industry economics (Higher Education Press, Beijing 2000)

[5]Yao Chunxiao, Zhao Wenqing: submitted to Journal of Journal of Tourism Economy (2010) 